\title{
Differential proMMP-2 and proMMP-9 Secretion in Human Pre-implantation Embryos at Day 5 of Development.
}

\author{
Mercedes Olvera-Valencia \\ Instituto Nacional de Perinatologia \\ Ricardo Josué Acuña-González \\ Instituto Nacional de Perinatologia \\ Esther lyune-Cojab \\ Instituto Nacional de Perinatologia \\ Paola Vázquez-Cárdenas \\ Hospital General Dr Manuel Gea Gonzales \\ Jorge Skiold López-Canales \\ Instituto Nacional de Perinatologia \\ Jair Lozano-Cuenca \\ Instituto Nacional de Perinatologia \\ Mauricio Osorio-Caballero \\ Instituto Nacional de Perinatologia \\ Héctor Flores-Herrera ( $\nabla$ h.flores@inper.gob.mx ) \\ Instituto Nacional de Perinatologia https://orcid.org/0000-0002-7604-6158
}

\section{Research}

Keywords: embryonic development, implantation, in vitro fertilization, matrix metalloproteinases, pregnancy

Posted Date: May 4th, 2021

DOI: https://doi.org/10.21203/rs.3.rs-435065/v1

License: (c) (i) This work is licensed under a Creative Commons Attribution 4.0 International License. Read Full License 


\section{Abstract}

Background: The most commonly used non-invasive criterion for evaluating the probable success of transferring in vitro human embryos for implantation is their morphological development. With this criterion, however, embryos in cellular arrests go unnoticed. Extracellular matrix metalloproteases type 2 (MMP-2) and MMP-9 are key markers of embryonic development and the implantation process, according to various animal studies. The current study investigated the proMMP-2 and proMMP-9 expression in the culture media developing human embryos that were transferred for implantation.

Methods: Forty-two patients were accepted in the Department of Reproductive Biology of a Hospital in México City, based on the Institutional inclusion criteria for in vitro fertilization. On day 5 of development, embryos were transferred to women, and the culture medium was stored at -70 to await assessment of the activity of proMMP-2 and proMMP-9 in substrate gel zymography.

Results: The patients showing embryo sac development were assigned to the pregnant group $(n=17)$ or non-pregnant $(\mathrm{n}=25)$. In both groups, the activity of proMMP-2 and proMMP-9 was evaluated in substrate gel zymography. Our results indicate for all 17 women able to achieve a full-term pregnancy, the activity band of proMMP-2 was found in the corresponding culture medium. For 11 of them, the band of proMMP-9. Regarding the other 25 patients, the expression band for proMMP-2 detected in 3 and that proMMP-9 in 11 individuals.

Conclusions: On day 5 of embryo development, the evaluation of proMMP-2 and proMMP-9 in the embryo culture medium is a reliable indicator of embryo quality and capacity to establish pregnancy.

\section{Background}

The success growth and implantation of blastocysts is a complex event involving maternal and embryonic signals $[1,2]$. Cytokines $[3,4]$, growth factors $[5,6]$, and matrix metalloproteinases $[7,8]$ are associated with an adequate interaction between the blastocyst and uterine endometrium after implantation $[9,10]$.

Taskin et al. (2012) detected the secretion of interleukin (IL)-1 $\beta$ in the culture media of human embryos at distinct stages of development [11]. Among the signaling pathways regulated by inflammatory cytokines is the activation of matrix metalloproteinases (MMPs) [12], a family of zinc-dependent endoproteases MMPs participate in tissue remodeling and the degradation of various proteins in the extracellular matrix including collagen $[13,14]$, elastin $[15,16]$, gelatin $[17,18]$, matrix glycoproteins and proteoglycans $[19$, 20]. The substrates degraded by MMPs are the basis of classifying the latter commonly known MMPs are stromelysin-1 (MMP-3), -2 (MMP-10), -3 (MMP-11), collagenase-1 (MMP-1), -2 (MMP-8), -3 (MMP-13), gelatin-A (MMP-2), and gelatin-B (MMP-9), matrilysin type I (MMP-7), and type II (MMP-26). Membranal type I (MMP-14, -15, -16, and - 24), and Type II (MMP-23) [21-23]. In addition to their role in pregnancy $[24,25]$. MMPs promote cell proliferation [26, 27], migration [28, 29], differentiation [30, 31]. 
Regarding the evaluation of embryo quality prior to implantation, there is as yet no quantitative method. Embryonic morphology is the criterion employed in clinical practice as a qualitative marker of the viability of embryos to be transferred to patients [32,33]. However, this method has not shown an acceptable clinical correlation, since even aneuploid embryos can have normal morphology, and some euploid embryos can have aberrant morphology [34]. Thus, the aim of present study, was to analyze the culture medium of embryos with good morphological development in order to determine whether significant differences exist in the expression of proMMP-2 and proMMP-9 between the groups of embryos with successful and implantation.

\section{Methods}

\section{Ethics statements}

The current protocol was reviewed and approved by the Ethics and Research Committees of the Instituto Nacional de Perinatología in México City (212250 - 22661). The purpose of the study was explained to all patients, and informed consent was signed by those who decided to participate.

\section{Patients}

Forty-two patients diagnosed with infertility were admitted to the Department of Reproductive Biology (Instituto Nacional de Perinatología) for in vitro fertilization. The following constituted the inclusion criteria: $\leq 37$ years of age, a regular menstrual cycle, a normal uterine cavity confirmed by hysteroscopy, an absence of intrauterine adhesion or inflammation, an endometrial thickness in the late follicular phase of $\geq 7 \mathrm{~mm}$ measured by ultrasonography, a normal ovarian reserve (follicle-stimulating hormone < $9.0 \mathrm{mU} / \mathrm{mL}$ ), a normal ovarian response to the stimulation protocols ( $>8$ oocytes retrieved in a controlled ovary hyperstimulation cycle), and the lack of hormone (estradiol/progesterone) treatment during the endometrial cycle.

\section{Hormonal stimulation of patients}

The patients received controlled ovarian stimulation with FSH/LH. When the follicular diameter measured $18 \mathrm{~mm}$, oocyte maturation was stimulated with human chorionic gonadotropin. Thirty-six hours later, follicular oocytes were obtained using ultrasound guidance.

\section{In vitro fertilization and developing embryos}

Oocytes were fertilized in vitro by exposing them to $1 \times 10^{6}$ capacitated spermatozoa/mL for 18 hours. This process was carried out in HTF/HEPES medium supplemented with $5 \%$ albumin under controlled conditions $\left(37^{\circ} \mathrm{C}, 54 \% \mathrm{CO}_{2}\right.$ and $95 \%$ air). Fertilization was assessed by the presence of a second polar corpuscle body. Oocytes were each maintained in $50 \mu \mathrm{L}$ of G-1 PLUS culture medium (Sweden). Morphological development was observed daily up to the 36 -cell stage (5 day), at which time the culture medium was retained for matrix metalloproteinase analysis. 
On day 5 of embryo development two embryos (with quality type I, II, or III quality) were transferred to the uterine cavity with Flexible Pass intrauterine transfer cannula based on the Soft Cook technique. The process was assisted by abdominal ultrasound guidance and a real-time, 5-MHz sector electronic array endovaginal test (Philips Epiq CVx; MO, USA).

\section{Blood samples}

Five milliliters of peripheral blood were obtained from the patients by puncture of the cephalic vein, placed in EDTA-K2 tubes (BD Vacutainer), and centrifuged at 14,000 rpm for 10 minutes. Serum was collected in Eppendorf tubes and stored at $-70^{\circ} \mathrm{C}$ until to quantification hormones assay.

\section{Assay to determine the levels of sex hormones}

All evaluations of hormones were performed in the central laboratory of the Instituto Nacional de Perinatología on the Modular Analytical apparatus cobas e 411 (Roche, USA). A commercially available assay kit was used to measure the serum levels of P4, E2, T4, FSH, LH, AMH, and hCG (Roche system, USA), with according to the manufacturer's recommendations and as previously described [35-37]. The lower limit of detection for these hormones was $0.4 \mathrm{ng} / \mathrm{mL}, 5.0 \mathrm{pg} / \mathrm{mL}, 0.025 \mathrm{pg} / \mathrm{mL}, 0.100 \mathrm{mlU} / \mathrm{mL}$, $0.100 \mathrm{mlU} / \mathrm{mL}$, and $0.2 \mathrm{ng} / \mathrm{mL}, 0.1 \mathrm{mlU} / \mathrm{mL}$, respectively. The intra-assay coefficient of variation was $3 \%$, $5 \%, 5 \%, 3 \%, 2 \%, 3 \%$, and $5 \%$ respectively.

\section{Determination of pregnancy outcome}

The serum concentration of P4, E2, T4, FSH, LH, AMH, and hCG was assessed 14 days after embryo transfer. The apparent successful implantation of the embryo and endometrial receptivity were confirmed by ultrasound, embryo sac development. In accordance with the finding of this analysis, the patients were assigned to one of two groups: with and without implanted embryos $(n=17$, pregnant and $n=25$, nonpregnant patients, respectively).

\section{Protein quantification and matrix metalloproteinase activity}

The concentration of proMMP-2 and proMMP-9 proteins in the culture media, indicating their secretion into the media by the embryos, was measured in the two groups by the colorimetric Bradford method [38] and activity using SDS-polyacrylamide gels with porcine gelatin $(1 \mathrm{mg} / \mathrm{mL})$, as described previously [39]. The internal control of electrophoretic mobility was a used a culture medium from U937 promyelocyte cells (ATCC, Manassas, VA, USA). Each sample was loaded with $0.75 \mu \mathrm{g}$ of protein and the activity band was captured with the EpiChemi Darkroom gel documentation system (UVP, CA, USA). Optical densitometry was quantified on the NIH ImageJ program.

\section{Statistical analysis}

Difference between the two groups of embryos (implanted vs. non-implanted) base on the mean optical density values of the corresponding culture media, were examined with the Student's t- test. All values are expressed as the mean $\pm S D$, and statistical significance was considered at $p \leq 0.05$. Statistical analysis was performed on GraphPad Prism version 8.0 (GraphPad Software, San Diego, CA, USA). STATA 
software was used to plot the receiver operating characteristic (ROC) curves and calculate the area under the curve (AUC-ROC) (StataCorp LLC; v16, TX, USA). The cutoff value selected (based on the ROC curve) was that at which the sensitivity and specificity were best and the distance to the top-left corner of the ROC curve was the least. Sensitivity, specificity, and positive and negative predictive values were determined on the STATA software.

\section{Results}

\section{Patient characteristics}

Table 1 shows the characteristics of the 42 patients were compared between the two groups: pregnant ( $\mathrm{n}$ = 17); and 2) non-pregnant $(n=25)$ patients. No significant difference existed in regard to any of these parameters: age $(p=0.23)$, body mass index $(p=0.43)$, and years of infertility $(p=0.39)$.

Table 1

Clinical data on the patients participating in the study.

\begin{tabular}{|llll|}
\hline Characteristics & $\begin{array}{l}\text { Pregnancy } \\
(\mathbf{n = 1 7 )}\end{array}$ & $\begin{array}{l}\text { Non-pregnancy } \\
(\mathbf{n}=\mathbf{2 5})\end{array}$ & $p$-value \\
\hline Age (years) & $35.7 \pm 2.4$ & $36.8 \pm 3.1$ & 0.23 \\
\hline BMI (Kg/mL) & $27.2 \pm 3.7$ & $26.3 \pm 3.2$ & 0.43 \\
\hline Year of infertility & $4.8 \pm 3.0$ & $5.4 \pm 3.2$ & 0.39 \\
\hline Number of transferred embryos & & & 0.085 \\
\hline $1, n(\%)$ & $0(0.0)$ & $4(10.0)$ & \\
\hline $2, n(\%)$ & $17(100)$ & $19(45)$ & 0.137 \\
\hline Quality of the transferred embryos & & & 0.04 \\
\hline I, $n(\%)$ & $7(22.0)$ & $4(10)$ & 0.001 \\
\hline II, $n(\%)$ & $25(71.0)$ & $25(60.0)$ & \\
\hline III, $n(\%)$ & $2(7.0)$ & $13(30.0)$ & 0.70 \\
\hline Hormone concentration in serum & & $1254.0 \pm 1149.2$ & 0.71 \\
\hline hCG & $2088.2 \pm 2300.4$ & $1674 \pm 513.3$ & 0.90 \\
\hline$E_{2}$ & $1496.7 \pm 793.9$ & $0.55 \pm 0.3$ & \\
\hline$P_{4}$ & $0.65 \pm 0.4$ & & \\
\hline
\end{tabular}

$\mathrm{BMI}$, body mass index. $\mathrm{hCG}$, human chorionic gonadotropin; $\mathrm{E}_{2}$, estradiol; $\mathrm{P}_{4}$, progesterone. The criterion for assigning patients to the groups was embryo sac development (or lack thereof). Data are reported as the mean \pm standard deviation. 


\section{Hormone profiling}

The concentration of hormone was compared between pregnant and non-pregnant patients (Table 2). No significant differences existed with respect to P4 on the day of final oocyte maturation $(p=0.664)$, E2 nofollicular phase $(p=0.684)$, and follicular phase $(p=0.326)$, T4 $(0.326), \mathrm{LH}(p=0.095)$, and the AntiMüllerian Hormone $(p=0.263)$; however, significant difference was indeed found for FSH $(p=0.011)$, and hCG $(p<0.0001 ;$ Table 2).

Table 2

Comparison of the hormonal concentration between women with implanted and non-implanted embryos.

\begin{tabular}{|llll|}
\hline Variable & $\begin{array}{l}\text { Pregnancy } \\
(\mathbf{n = 1 7})\end{array}$ & $\begin{array}{l}\text { Non-pregnancy } \\
(\mathbf{n = 2 5})\end{array}$ & $p$-value \\
\hline P4 on day of final oocytes maturation, $(\mathrm{ng} / \mathrm{mL})$ & $0.49 \pm 0.20$ & $0.45 \pm 0.28$ & 0.664 \\
\hline E2 no-follicular phase, $(\mathrm{pg} / \mathrm{mL})$ & $60.7 \pm 16.4$ & $63.7 \pm 2710$ & 0.684 \\
\hline E2 follicular phase, $(\mathrm{pg} / \mathrm{mL})$ & $1368.0 \pm 582.1$ & $1889.0 \pm 849.3$ & 0.326 \\
\hline T4 follicular phase, $(\mathrm{pg} / \mathrm{mL})$ & $50.4 \pm 20.5$ & $46.2 \pm 7.8$ & 0.336 \\
\hline FSH follicular phase, $(\mathrm{mlU} / \mathrm{mL})$ & $4.6 \pm 1.3$ & $6.3 \pm 2.5$ & 0.011 \\
\hline LH follicular phase, $(\mathrm{mlU} / \mathrm{mL})$ & $4.9 \pm 1.2$ & $5.8 \pm 1.6$ & 0.095 \\
\hline AMH, $(\mathrm{ng} / \mathrm{mL})$ & $1.56 \pm 0.61$ & $1.39 \pm 0.37$ & 0.263 \\
\hline hCG, $(\mathrm{mlU} / \mathrm{mL})$ & $61.8 \pm 32.7$ & $2.7 \pm 1.4$ & $<0.0001$ \\
\hline Data are $p r e s e n t e d$ as the $\mathrm{mean} \pm$ standard deviation. & & \\
\hline
\end{tabular}

Expression of proMMP-2 and proMMP-9 in the culture medium of the embryos.

On day 5 of development, the embryo was transferred to the patients and the secretion profile of proMMP-2 and proMMP-9 was determined in the culture medium (Fig. 1).

The presence of proMMP-2 was detected in the culture media corresponding to $100 \%$ of the pregnant patients (17 of 17; lane 1 to 14) and in $11 \%$ (3 of 25; lane 15 to 57 ) of the non-pregnant patients (Fig. 1). The latter group included three women who became pregnant and underwent a spontaneous abortion (P52, P57, and P58; Fig. 1). The optical density of proMMP-2 quantified for each of the activity bands (Fig. 2). Was significantly (1.4-fold) lower in the three non-pregnant patients with proMMP-2 expression than in the pregnant women (Fig. $2 ; p=0.045$ ). 
On the other hand, proMMP-9 expression was found in the culture media corresponding to 11 of 14 pregnant and $39 \%$ of non-pregnant patients (11 of 25). The optical density of the bands of proMMP-9 showed a significantly (1.2-fold; Fig. 2) lower value in the culture media corresponding to the 11 nonpregnant patients with proMMP-9 expression versus the culture media corresponding to the 11 pregnant women with proMMP-9 expression (Fig. 2; $=0.002$ ).

Predictive values of proMMP-2 and proMMP-9 in the culture medium of developing embryos from pregnant patients.

The ROC curve was used to evaluate the sensitivity and specificity of proMMP-2 and proMMP-9 for determining the capacity of transferred embryos to result in pregnancy (Fig. 3). For proMMP-2, the optical density of 423 was taken as the cutoff value and showed statistical significance $(p=0.02)$ which exhibited a sensitivity of $100 \%$ and a specificity of $100 \%$. For proMMP-9, the optical density of 550 was adopted as the cutoff value and showed statistical significance $(p=0.0035)$ having a sensitivity of $81.8 \%$ and a specificity of $72.7 \%$.

\section{Discussion}

MMPs play an important role in the remodeling of different structural and support components during ovulation [40,41] decidualization [42, 43], and implantation [44-46]. The main findings of the present study can be summarized in five points in relation to the activity of proMMP-2 and proMMP-9 in the culture media of the embryos on day 5 of their development 1) the activity of proMMP-2 was found in 14 of 14 culture media corresponding to the patients who achieved a full-term pregnancy and in 3 of 25 culture media associated with women who did not have this outcome. It was 1.4-fold greater in the former group; 2 ) The activity of proMMP-2 was observed in 11 of 14 culture media corresponding to the patients who carried their pregnancy to term and in 11 of 25 culture media associated with women who did not have this outcome. It was 1.2-fold greater in the former group (Fig. 1); 3) In the three patients who did not carry their pregnancy to term, only proMMP-9 activity was detected; 4) the activity of both proMMP-2 and proMMP-9 was identified in three non-pregnant patients who had some pre-pregnancy complications (Fig. 1); and 5) There were no significant differences in the concentration of the hormones HCG, E2, or P4 between pregnant and non-pregnant patients (Table 1).

Gu et al. (2015) reported the concentration of the active form of MMP-9 at $0.698 \pm 0.022 \mathrm{ng} / \mathrm{mL}$ in the culture medium of developing human embryos, which resulted in pregnancy for $77.0 \%$ of the participating patients [47-49]. According to the present study, the activity of proMMP-2 and proMMP-9 (Fig. 2) was significantly higher in the culture media of the embryos yielding a full-term pregnancy than in the culture media of the other cases (Table 1). The culture media exhibited a 1.4-fold greater proMMP-2 activity $(\mathrm{p}=$ $0.045)$ for the embryos generating a full term pregnancy compared the other cases $(3 / 25)$ showing proMMP-2 activity. Similarly, the culture medium displayed a 1.2-fold greater proMMP-9 activity $(\mathrm{p}=$ $0.002)$ for the embryos engendering a full term pregnancy $(11 / 14)$ compared to the other cases $(11 / 28)$, considering the media with proMMP-9 activity. 
A conceptual model is herein provided (Fig. 4) how MMPs are activated by epidermal growth factors [47], interleukin (IL) -1 $\beta$, and tumor necrosis factor (TNF)- $\alpha[50,51]$. Sequeira et al. (2015) reported a significantly (15.4-fold) greater value for the level of IL-1 $\beta$ in the culture media of developing human embryos that became implanted in patients versus the culture media of non-implanted embryos (0.55 \pm $0.25 \mathrm{pg} / \mathrm{mL}$ ), finding implantation in $42.0 \%$ of the total participants [52].

In the first and second trimesters of pregnancy, syncytiotrophoblast cells have been described to secrete a 2.4- and 3.8-fold higher amount of IL-1 $\beta$, respectively, than the pre-pregnancy level. The secretion of IL-1 $\beta$ is associated with an increase in MMP-9 expression [53]. After interacting with its receptor, IL-1 $\beta$ regulates the signaling pathway that involves the activation of the mitogen-activated protein kinase (MAPK), p38 MAPK, c-Jun N-terminal kinase (JNK), and the extracellular regulatory kinase (ERK) [54, 55]. As a consequence, IL-1 $\beta$ promotes the activation of nuclear factor kappa-beta (NFk $\beta$ ) and the expression of MMPs [56].

The collagenolytic activity of MMPs is regulated by the specific tissue inhibitors of these proteinases [49, 57]. Cytotrophoblast cells, treated with $50 \mathrm{nM}$ of their tissue inhibitor, known as tissue inhibitor of metalloproteinase-2 (TIMP-2) exhibit an up to 40\% reduction in invasiveness according to Librach (1991) $[51,58]$. The present results showed a 1.4-fold and 1.2-fold decrease in the activity of proMMP-2 and proMMP-9 respectively (Fig. 2), in the culture media corresponding to the cases of patients who were pregnant but did not carry to term. However, the expression of TIMPs was not herein evaluated in the culture medium of developing embryos. It would be interesting to determine the MMP/TIMP relationship is involved in the mechanism responsible for regulating the progress of implantation and pregnancy.

Recently, localized polymorphisms identified in the promoter region of MMP-2 (-1306 C/T; rs 243865) and MMP-9 (-1562 C/T; rs 3918242) were found to induce changes in the levels of transcription and or expression of the protein. These mutations have been proposed as a risk factor for spontaneous abortion $[50,59]$. Regarding the three patients of the present study with implanted embryos that spontaneously aborted (P52, P57, and P58), the corresponding culture media displayed proMMP-2 and proMMP-9 (Fig. 2) activity. Future research should explore the possible relation of such pregnancy complications to mutations.

MMP-2 has the ability to degrade fibronectin, elastin, and collagen type IV, V, VII, and. In contrast MMP-9 degrades proteoglycans, elastin, and collagen I, IV, V, and XI [51, 60-62] which allows the cytotrophoblast cells to invade the endometrium to prepare the way for implantation) [63] (Fig. 5). During the implantation window, according to in vivo (in animal models [64] and in vitro studies [65], the epithelial cadherin-like binding protein (E-cadherin) enables the embryo to adhere to the endometrial epithelium, which is degraded by MMP- 9 [66]. Hence, previous reports evidence a key role by MMP-2 and MMP-9 in embryonic development. The present analysis based on the cutoff points of the ROC curve for both proteinases suggests that their evaluation in the culture medium of developing embryos has plausible predictive power in relation to the success of implantation. 


\section{Conclusions}

These results of the current contribution demonstrate the feasibility of detecting proMMP-2 and proMMP9 activity in the culture medium of embryos on day 5 of development by using in ge/ zymography. Additionally, such activity is associated with the capacity of embryos for implantation. Thus this evaluation could serve as a non-invasive method for determining the viability of human embryos developed in vitro conditions.

\section{Abbreviations}

BMI: Body mass index; IVF: in vitro fertilization; MMP: matrix metalloproteases.

\section{Declarations}

\section{Ethics approval and informed consent}

Each patient was informed that, by agreeing to participate in the study, the culture medium of the embryo would be used to perform MMPs assays after embryo transfer, and that this procedure would not affect the development of the embryos. All candidates signed the consent form after the explication. The present protocol was reviewed and approved by the Ethics and Research Committees of the Instituto Nacional de Perinatología (212250-22661).

\section{Consent for publication}

All authors carefully read the final version of the manuscript and gave their permission to submit to the journal of Reproductive Biology and Endocrinology.

\section{Availability of data and materials}

All of the relevant information from the study is described in the manuscript.

\section{Competing Interest}

All authors declare that they have no competing interests with respect to the research, or the authorship publication of this article.

\section{Funding}

The current study was supported by a grant (212250-22661 assigned to HFH) from the Instituto Nacional de Perinatología "Isidro Espinosa de lo Reyes" of Ciudad de México, México. The institute was not involved in any stage, and therefore has no conflict of interest with the content of the manuscript.

\section{Authors' contributions}


MOV performed the quantification of hormones in the serum of the patients. MOV and RJAG carry out the evaluating of MMP activity. RJAG and EIC performed in vitro fertilization, obtained the culture medium for the development embryos of the embryos. RJAG monitoring pregnancy and gestational sac formation. PVC performed the statistical analysis of the ROC curve, and participated in the discussion of results and writing of manuscript. MOV, RJAG, JSLC and JLC participated in the analysis and discussion of the results. MOC performed the analysis of MMP activity and participated in the writing of the manuscript. $\mathrm{HFH}$ participated in the design of the study, analysis of results, and writing the manuscript, as well as obtaining financial and material support for the study.

\section{Acknowledgments}

In the development of this study, we did not have the advice of external researchers.

\section{References}

1. Fritz R, Jain C, Armant DR: Cell signaling in trophoblast-uterine communication. Int J Dev Bio/2014, 58:261-271.

2. Matsumoto $H$, Fukui E, Yoshizawa M: Molecular and cellular events involved in the completion of blastocyst implantation. Reprod Med Biol 2016, 15:53-58.

3. Krussel JS, Simon C, Rubio MC, Pape AR, Wen Y, Huang HY, Bielfeld P, Polan ML: Expression of interleukin-1 system mRNA in single blastomeres from human preimplantation embryos. Hum Reprod 1998, 13:2206-2211.

4. Prutsch N, Fock V, Haslinger P, Haider S, Fiala C, Pollheimer J, Knofler M: The role of interleukin-1beta in human trophoblast motility. Placenta 2012, 33:696-703.

5. Paria BC, Elenius K, Klagsbrun M, Dey SK: Heparin-binding EGF-like growth factor interacts with mouse blastocysts independently of ErbB1: a possible role for heparan sulfate proteoglycans and ErbB4 in blastocyst implantation. Development 1999, 126:1997-2005.

6. Zeng F, Kloepfer LA, Finney C, Diedrich A, Harris RC: Specific endothelial heparin-binding EGF-like growth factor deletion ameliorates renal injury induced by chronic angiotensin II infusion. Am J Physiol Renal Physiol 2016, 311:F695-F707.

7. Nissinen L, Kahari VM: Matrix metalloproteinases in inflammation. Biochim Biophys Acta 2014, 1840:2571-2580.

8. Sternlicht MD, Werb Z: How matrix metalloproteinases regulate cell behavior. Annu Rev Cell Dev Biol 2001, 17:463-516.

9. Massimiani M, Lacconi V, La Civita F, Ticconi C, Rago R, Campagnolo L: Molecular Signaling Regulating Endometrium-Blastocyst Crosstalk. Int J Mol Sci 2019, 21.

10. Tazuke SI, Giudice LC: Growth factors and cytokines in endometrium, embryonic development, and maternal: embryonic interactions. Semin Reprod Endocrino/ 1996, 14:231-245. 
11. Taskin EA, Baltaci V, Cagiran G, Aytac R: Detection of IL-1beta in culture media supernatants of preimplantation human embryos; its relation with embryo grades and development. Gynecol Endocrinol 2012, 28:296-298.

12. Chen Q, Jin M, Yang F, Zhu J, Xiao Q, Zhang L: Matrix metalloproteinases: inflammatory regulators of cell behaviors in vascular formation and remodeling. Mediators Inflamm 2013, 2013:928315.

13. Shekhter AB, Balakireva AV, Kuznetsova NV, Vukolova MN, Litvitsky PF, Zamyatnin AA, Jr.: Collagenolytic Enzymes and their Applications in Biomedicine. Curr Med Chem 2019, 26:487-505.

14. Shin JW, Kwon SH, Choi JY, Na JI, Huh CH, Choi HR, Park KC: Molecular Mechanisms of Dermal Aging and Antiaging Approaches. Int J Mol Sci 2019, 20.

15. Van Doren SR: Matrix metalloproteinase interactions with collagen and elastin. Matrix Bio/2015, 4446:224-231.

16. Yadav RK, Gupta SP, Sharma PK, Patil VM: Recent advances in studies on hydroxamates as matrix metalloproteinase inhibitors: a review. Curr Med Chem 2011, 18:1704-1722.

17. Le NT, Xue M, Castelnoble LA, Jackson CJ: The dual personalities of matrix metalloproteinases in inflammation. Front Biosci 2007, 12:1475-1487.

18. Zitka O, Kukacka J, Krizkova S, Huska D, Adam V, Masarik M, Prusa R, Kizek R: Matrix metalloproteinases. Curr Med Chem 2010, 17:3751-3768.

19. Pietraszek-Gremplewicz K, Karamanou K, Niang A, Dauchez M, Belloy N, Maquart FX, Baud S, Brezillon S: Small leucine-rich proteoglycans and matrix metalloproteinase-14: Key partners? Matrix Biol 2019, 75-76:271-285.

20. Theocharis AD, Manou D, Karamanos NK: The extracellular matrix as a multitasking player in disease. FEBS J 2019, 286:2830-2869.

21. Brew K, Nagase H: The tissue inhibitors of metalloproteinases (TIMPs): an ancient family with structural and functional diversity. Biochim Biophys Acta 2010, 1803:55-71.

22. Laronha H, Caldeira J: Structure and Function of Human Matrix Metalloproteinases. Cells 2020, 9.

23. Visse R, Nagase H: Matrix metalloproteinases and tissue inhibitors of metalloproteinases: structure, function, and biochemistry. Circ Res 2003, 92:827-839.

24. Cohen M, Bischof P: Factors regulating trophoblast invasion. Gynecol Obstet Invest 2007, 64:126130.

25. Stojanovic N, Lewandowski K, Salata I, Bienkiewicz M, Tuck S, Prelevic G, Press M: Serum levels of matrix metalloproteinases MMP-2 and MMP-9 and their inhibitors in women with glucose intolerance in pregnancy and normal controls. Gynecol Endocrinol 2010, 26:201-207.

26. Quintero-Fabian S, Arreola R, Becerril-Villanueva E, Torres-Romero JC, Arana-Argaez V, Lara-Riegos J, Ramirez-Camacho MA, Alvarez-Sanchez ME: Role of Matrix Metalloproteinases in Angiogenesis and Cancer. Front Oncol 2019, 9:1370.

27. Zhang X, Huang S, Guo J, Zhou L, You L, Zhang T, Zhao Y: Insights into the distinct roles of MMP-11 in tumor biology and future therapeutics (Review). Int J Oncol 2016, 48:1783-1793. 
28. Bischof P, Meisser A, Campana A: Control of MMP-9 expression at the maternal-fetal interface. $J$ Reprod Immunol 2002, 55:3-10.

29. Pollheimer J, Fock V, Knofler M: Review: the ADAM metalloproteinases - novel regulators of trophoblast invasion? Placenta 2014, 35 Suppl:S57-63.

30. Chan ZC, Oentaryo MJ, Lee CW: MMP-mediated modulation of ECM environment during axonal growth and NMJ development. Neurosci Lett 2020, 724:134822.

31. Gorter RP, Baron W: Matrix metalloproteinases shape the oligodendrocyte (niche) during development and upon demyelination. Neurosci Lett 2020, 729:134980.

32. Capalbo A, Rienzi L, Cimadomo D, Maggiulli R, Elliott T, Wright G, Nagy ZP, Ubaldi FM: Correlation between standard blastocyst morphology, euploidy and implantation: an observational study in two centers involving 956 screened blastocysts. Hum Reprod 2014, 29:1173-1181.

33. Minasi MG, Colasante A, Riccio T, Ruberti A, Casciani V, Scarselli F, Spinella F, Fiorentino F, Varricchio MT, Greco E: Correlation between aneuploidy, standard morphology evaluation and morphokinetic development in 1730 biopsied blastocysts: a consecutive case series study. Hum Reprod 2016, 31:2245-2254.

34. Lagalla C, Tarozzi N, Sciajno R, Wells D, Di Santo M, Nadalini M, Distratis V, Borini A: Embryos with morphokinetic abnormalities may develop into euploid blastocysts. Reprod Biomed Online 2017, 34:137-146.

35. Baker VL, Rone HM, Pasta DJ, Nelson HP, Gvakharia M, Adamson GD: Correlation of thyroid stimulating hormone (TSH) level with pregnancy outcome in women undergoing in vitro fertilization. Am J Obstet Gynecol 2006, 194:1668-1674; discussion 1674-1665.

36. Csemiczky G, Wramsby H, Landgren BM: Luteal phase oestradiol and progesterone levels are stronger predictors than follicular phase follicle stimulating hormone for the outcome of in-vitro fertilization treatment in women with tubal infertility. Hum Reprod 1996, 11:2396-2399.

37. Penarrubia J, Fabregues F, Manau D, Creus M, Casals G, Casamitjana R, Carmona F, Vanrell JA, Balasch J: Basal and stimulation day 5 anti-Mullerian hormone serum concentrations as predictors of ovarian response and pregnancy in assisted reproductive technology cycles stimulated with gonadotropin-releasing hormone agonist-gonadotropin treatment. Hum Reprod 2005, 20:915-922.

38. Bradford MM: A rapid and sensitive method for the quantitation of microgram quantities of protein utilizing the principle of protein-dye binding. Anal Biochem 1976, 72:248-254.

39. Flores-Herrera H, Garcia-Lopez G, Diaz NF, Molina-Hernandez A, Osorio-Caballero M, Soriano-Becerril $D$, Zaga-Clavellina V: An experimental mixed bacterial infection induced differential secretion of proinflammatory cytokines (IL-1beta, TNFalpha) and proMMP-9 in human fetal membranes. Placenta 2012, 33:271-277.

40. Rosewell KL, Al-Alem L, Zakerkish F, McCord L, Akin JW, Chaffin CL, Brannstrom M, Curry TE, Jr.: Induction of proteinases in the human preovulatory follicle of the menstrual cycle by human chorionic gonadotropin. Fertil Steril 2015, 103:826-833. 
41. Smith MF, Ricke WA, Bakke LJ, Dow MP, Smith GW: Ovarian tissue remodeling: role of matrix metalloproteinases and their inhibitors. Mol Cell Endocrinol 2002, 191:45-56.

42. Jones RL, Findlay JK, Farnworth PG, Robertson DM, Wallace E, Salamonsen LA: Activin A and inhibin A differentially regulate human uterine matrix metalloproteinases: potential interactions during decidualization and trophoblast invasion. Endocrinology 2006, 147:724-732.

43. Sharma S, Godbole G, Modi D: Decidual Control of Trophoblast Invasion. Am J Reprod Immunol 2016, 75:341-350.

44. Clark PA, Xie J, Li S, Zhang X, Coonrod S, Roberson MS: Matrix metalloproteinase 9 is a distal-less 3 target-gene in placental trophoblast cells. Am J Physiol Cell Physio/2013, 305:C173-181.

45. Shokry M, Omran OM, Hassan HI, Elsedfy GO, Hussein MR: Expression of matrix metalloproteinases 2 and 9 in human trophoblasts of normal and preeclamptic placentas: preliminary findings. Exp Mol Pathol 2009, 87:219-225.

46. Wang H, Wen Y, Mooney S, Li H, Behr B, Polan ML: Matrix metalloproteinase and tissue inhibitor of matrix metalloproteinase expression in human preimplantation embryos. Fertil Steril 2003, 80 Suppl 2:736-742.

47. Gu J, Han $\mathrm{CH}, \mathrm{Hu} F \mathrm{~F}$, Wang YB, Cao YJ: The correlation analysis of human embryonic MMP-9 secretion and embryo quality. Eur Rev Med Pharmacol Sci 2015, 19:2354-2358.

48. Huang HY, Wen Y, Irwin JC, Kruessel JS, Soong YK, Polan ML: Cytokine-mediated regulation of 92kilodalton type IV collagenase, tissue inhibitor or metalloproteinase-1 (TIMP-1), and TIMP-3 messenger ribonucleic acid expression in human endometrial stromal cells. J Clin Endocrinol Metab 1998, 83:1721-1729.

49. Woessner JF, Jr.: Matrix metalloproteinases and their inhibitors in connective tissue remodeling. FASEB J 1991, 5:2145-2154.

50. Basu J, Agamasu E, Bendek B, Salafia CM, Mishra A, Lopez JV, Kroes J, Dragich SC, Thakur A, Mikhail M: Correlation Between Placental Matrix Metalloproteinase 9 and Tumor Necrosis Factoralpha Protein Expression Throughout Gestation in Normal Human Pregnancy. Reprod Sci 2018, 25:621-627.

51. Librach CL, Werb Z, Fitzgerald ML, Chiu K, Corwin NM, Esteves RA, Grobelny D, Galardy R, Damsky $\mathrm{CH}$, Fisher SJ: 92-kD type IV collagenase mediates invasion of human cytotrophoblasts. $\mathrm{J}$ Cell Biol 1991, 113:437-449.

52. Sequeira K, Espejel-Nunez A, Vega-Hernandez E, Molina-Hernandez A, Grether-Gonzalez P: An increase in IL-1 beta concentrations in embryo culture-conditioned media obtained by in vitro fertilization on day 3 is related to successful implantation. J Assist Reprod Genet 2015, 32:16231627.

53. Librach CL, Feigenbaum SL, Bass KE, Cui TY, Verastas N, Sadovsky Y, Quigley JP, French DL, Fisher SJ: Interleukin-1 beta regulates human cytotrophoblast metalloproteinase activity and invasion in vitro. J Biol Chem 1994, 269:17125-17131. 
54. Sondergaard BC, Schultz N, Madsen SH, Bay-Jensen AC, Kassem M, Karsdal MA: MAPKs are essential upstream signaling pathways in proteolytic cartilage degradation-divergence in pathways leading to aggrecanase and MMP-mediated articular cartilage degradation. Osteoarthritis Cartilage 2010, 18:279-288.

55. Vincenti MP, Brinckerhoff CE: Transcriptional regulation of collagenase (MMP-1, MMP-13) genes in arthritis: integration of complex signaling pathways for the recruitment of gene-specific transcription factors. Arthritis Res 2002, 4:157-164.

56. Liacini A, Sylvester J, Li WQ, Huang W, Dehnade F, Ahmad M, Zafarullah M: Induction of matrix metalloproteinase-13 gene expression by TNF-alpha is mediated by MAP kinases, AP-1, and NFkappaB transcription factors in articular chondrocytes. Exp Cell Res 2003, 288:208-217.

57. Zhu JY, Pang ZJ, Yu YH: Regulation of trophoblast invasion: the role of matrix metalloproteinases. Rev Obstet Gynecol 2012, 5:e137-143.

58. Bischof P, Campana A: A putative role for oncogenes in trophoblast invasion? Hum Reprod 2000, 15 Suppl 6:51-58.

59. Barisic A, Devic Pavlic S, Ostojic S, Pereza N: Matrix metalloproteinase and tissue inhibitors of metalloproteinases gene polymorphisms in disorders that influence fertility and pregnancy complications: A systematic review and meta-analysis. Gene 2018, 647:48-60.

60. Iwahashi M, Muragaki Y, Ooshima A, Yamoto M, Nakano R: Alterations in distribution and composition of the extracellular matrix during decidualization of the human endometrium. $J$ Reprod Fertil 1996, 108:147-155.

61. Kisalus LL, Herr JC, Little CD: Immunolocalization of extracellular matrix proteins and collagen synthesis in first-trimester human decidua. Anat Rec 1987, 218:402-415.

62. Mylona P, Kielty CM, Hoyland JA, Aplin JD: Expression of type VI collagen mRNAs in human endometrium during the menstrual cycle and first trimester of pregnancy. $J$ Reprod Fertil 1995, 103:159-167.

63. Sharma MR, Periandythevar P, Shapiro BH: Spurious observation of splenic cyp2b1 expression. Drug Metab Dispos 2003, 31:1074-1076.

64. Liu G, Zhang X, Lin H, Wang H, Li Q, Ni J, Zhu C: Effects of E-cadherin on mouse embryo implantation and expression of matrix metalloproteinase-2 and -9. Biochem Biophys Res Commun 2006, 343:832838.

65. Zhang Z, Zhang L, Jia L, Cui S, Shi Y, Chang A, Zeng X, Wang P: AP-2alpha suppresses invasion in BeWo cells by repression of matrix metalloproteinase-2 and -9 and up-regulation of E-cadherin. $\mathrm{Mol}$ Cell Biochem 2013, 381:31-39.

66. Maia-Filho VO, Rocha AM, Ferreira FP, Bonetti TC, Serafini P, Motta EL: Matrix metalloproteinases 2 and 9 and ecadherin expression in the endometrium during the implantation window of infertile women before in vitro fertilization treatment. Reprod Sci 2015, 22:416-422.

\section{Figure}


Figure 5 is not available with this version.

\section{Figures}

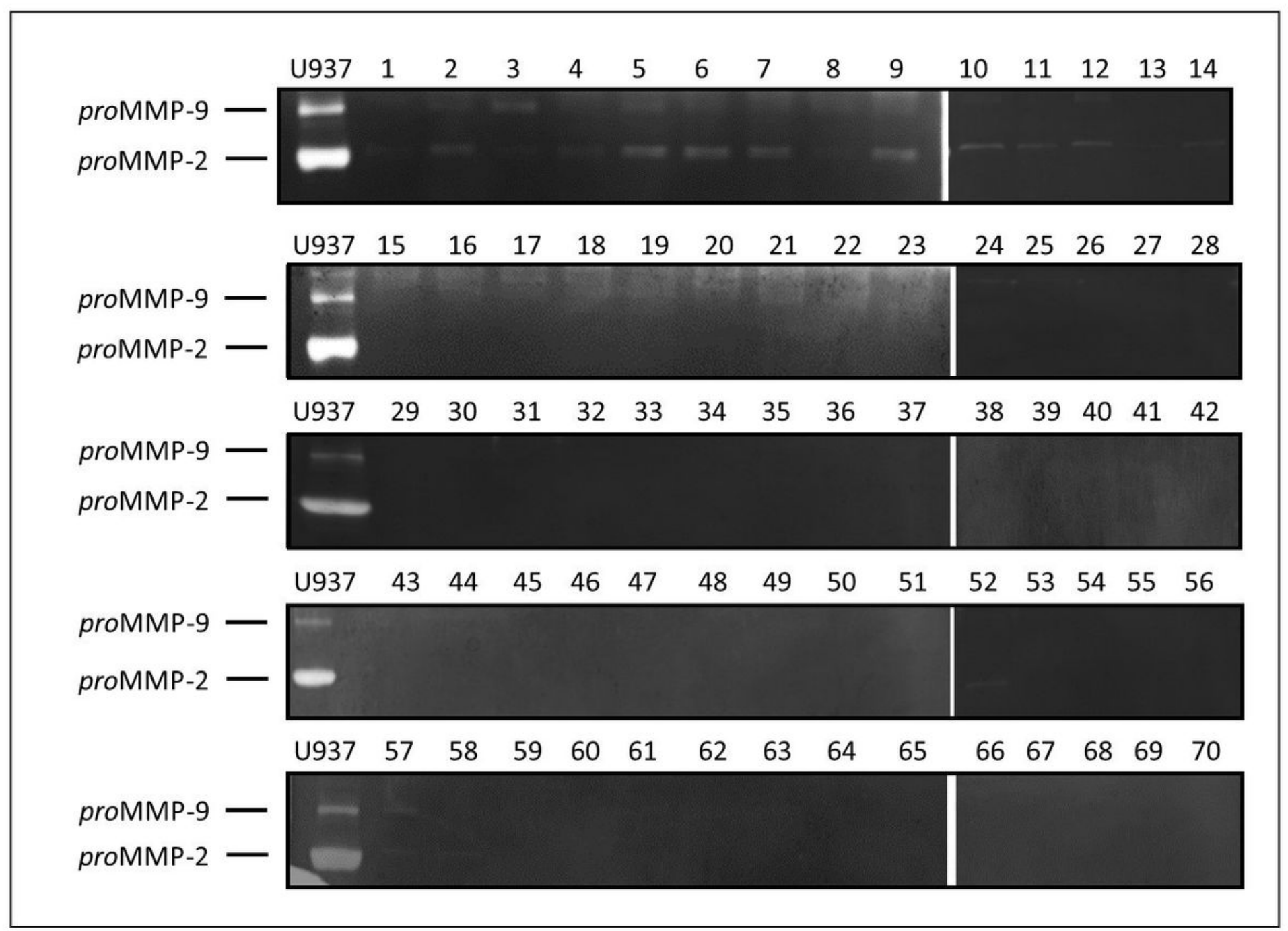

\section{Figure 1}

Activity of proMMP-2 and proMMP-9 in the culture medium of human embryos on day 5 of development. The culture medium from both implanted (pregnant patients; lanes 1-14) and non-implanted embryos (non-pregnant patients; lanes 15-70) was analyzed using gel. The activity of proMMP-2 (62 KDa) and proMMP-9 (92 KDa) was identified with respect to the electrophoretic mobility of the culture medium of the promyelocyte cell line (ATCC, U937), as previously reported by Flores-Herrera [36]. 


\section{proMMP-2}

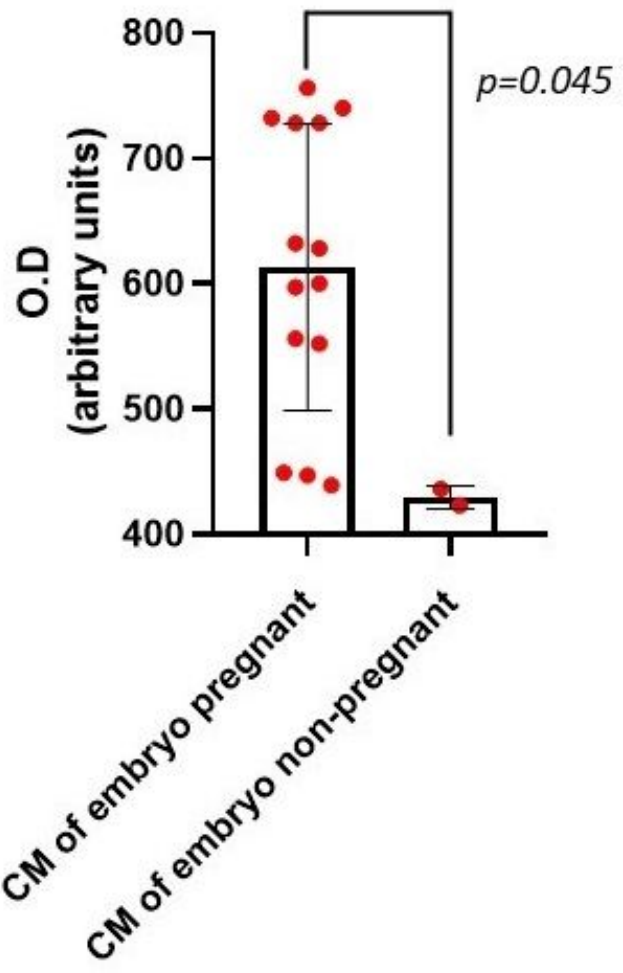

proMMP-9

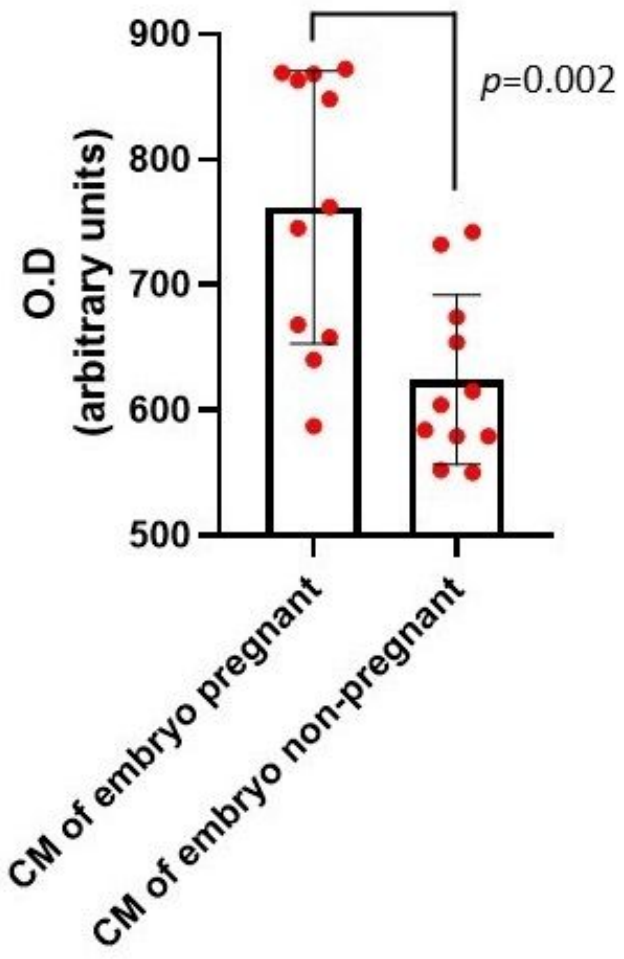

Figure 2

Optical density of proMMP-2 and proMMP-9. The points indicate the values of each activity band for implanted (pregnant patients, $n=14$ ) and non-implanted embryos (non-pregnant patients, $n=28$ ). Optical density (O.D) was determined using the Jlmage program (USA). 

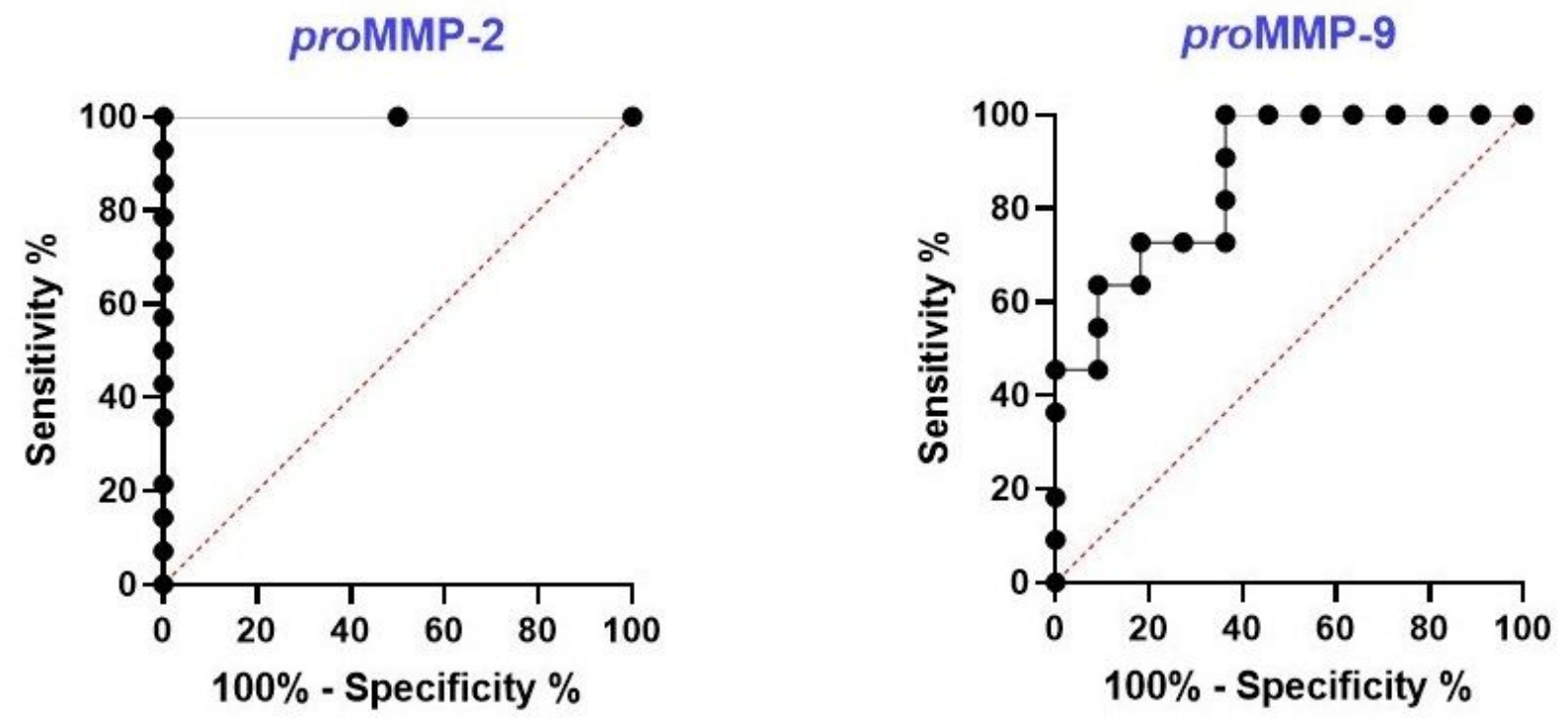

Figure 3

Predictive values of the ROC curves. The cutoff value selected (based on the ROC curve) was that at which the sensitivity and specificity were best for proMMP-2 and proMMP-9 as biomarkers of the success of implantation.

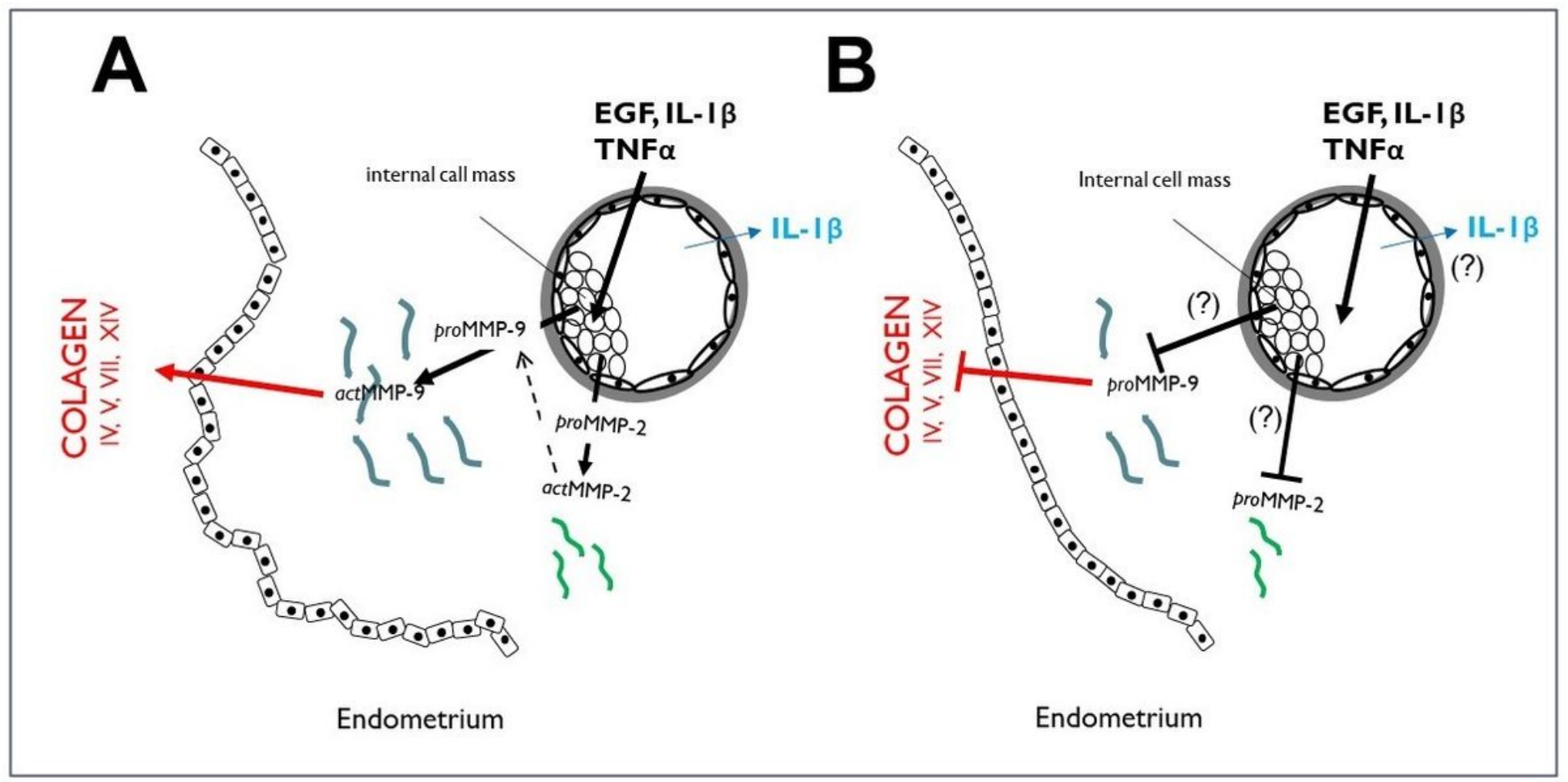

Figure 4 
Model of active proMMP-2 and proMMP-9 secreted from embryos into the culture medium. The developing embryos secrete interleukin type 1-beta (IL-1 $\beta$ ) [49], tumor necrosis factor-alpha (TNFa) [53, 64] and epidermal growth factor (EGF) [65], promoting the expression of the collagenolytic protein extracellular matrix $[45,66]$. The actMMP-2 protein form has been shown to remove propeptides associated with the catalytic site of proMMP-9, leading to activation of its degradative function $[67,68]$. 